\title{
CONSIDERAÇÕES E OBSERVAÇÕES SOBRE A AUTONOMIA DE APRENDIZES DE FRANCÊS LINGUA ESTRANGEIRA (FLE).
}

\author{
Thaís Andrade LIMA \\ Josilene Pinheiro MARIZ
}

\section{Resumo}

No contexto sociointeracionista do ensino/aprendizagem de uma língua estrangeira, busca-se não apenas o desenvolvimento das competências lingüísticas, culturais e textuais; mas, uma focalização da importância do aprendiz no processo, permitindo que ele desenvolva atitudes autônomas na sua aprendizagem. Mas, o que é autonomia na aprendizagem? Há estratégias para desenvolver a autonomia? Qual é o papel do professor nesse contexto? Este trabalho busca discutir essas, dentre outras questões. Os dados foram coletados a partir de observação de aulas e de aplicação de questionários em duas turmas de Francês, de alunos cujos objetivos eram diferentes, mas no mesmo nível de aprendizagem (A1, segundo o Quadro Europeu Comum de Referência para as Línguas 2001). Com base nas observações das aulas e nas análises dos dados, procuramos identificar quais eram as concepções, crenças e as estratégias utilizadas pelos aprendizes de FLE para, a partir de então, observar o grau de autonomia dos alunos. Após ponderações, apontamos para a necessidade de um estudo que focalizasse as ações pedagógicas do professor no contexto de ensino-aprendizagem de FLE, a fim de observar como suas práticas refletem na construção de comportamentos autônomos por parte de aprendizes.

Palavras-chave: autonomia; FLE; formação do professor, estratégias de aprendizagem.

\section{Résumé}

Dans le cadre socio-interactioniste de l'enseignement / apprentissage d'une langue étrangère, on ne vise pas seulement le développement des compétences linguistiques, culturelles et textuelles; mais on vise également l'importance de l'apprenti dans le processus, lui permettant de développer des attitudes autonomes dans son apprentissage. Mais qu'est l'autonomie dans l'apprentissage? Il existe des stratégies visant à développer l'autonomie? Quel est le rôle de l'enseignant dans ce contexte? Cet article traite de ces entreprises, entre autres. Les données ont été recueillies à partir de l'observation de classes et de l'application des questionnaires dans deux classes de français, pour les étudiants dont les objectifs étaient différents, mais qui étaient au même niveau de l'apprentissage (A1, selon le Cadre Européen Commun de Référence pour les Langues, 2001). Basées sur les observations des classes et sur l'analyse de données, on a cherché d'identifier quelles sont les idées, les croyances et les stratégies utilisées par les apprentis de FLE pour, depuis lors, constater le degré d'autonomie des étudiants. Après des considérations, on se tourne vers la nécessité d'une étude qui met l'accent sur les actions de l'enseignant, dans le contexte de l'enseignement/ apprentissage du FLE, ayant le but d'observer leurs pratiques lors de la construction d'un comportement autonome par les apprentis.

Mots-clés: autonomie; FLE; formation de formateurs; stratégies d’apprentissage.

\section{Introdução}

A partir da década de 1980 observamos mudanças significativas no processo de ensino-aprendizagem, pois a atenção passa a ser centrada no aprendiz e não mais no 
professor. O primeiro, agora, assume uma atitude ativa e passa a ser encarregado da sua própria aprendizagem de maneira autônoma; o segundo, por sua vez, deixa de ser controlador do processo e passa a estimular a aprendizagem espontânea (BAILLY e COHEN, 2007).

Dentro dessa perspectiva, observamos duas modificações fundamentais no contexto de aprendizagem: "modificação da definição do saber a se adquirir e modificação das relações entre o aprendiz e o saber” (ANDRÉ, 1989, p. 115). Em relação à primeira, o aluno passa a determinar o que quer aprender e como fazê-lo, partindo de critérios pessoais e em relação às situações comunicativas que lhe são oferecidas; estabelecendo, dessa forma, um foco no sentido, no significado e na interação entre sujeitos. No que diz respeito à relação aprendiz/saber, o aluno se insere numa realidade que ele mesmo pode construir e dominar, saindo da antiga dependência e passividade, podendo se responsabilizar pela sua própria aprendizagem.

Nesse âmbito, consideramos que as chances de sucesso na aprendizagem de uma língua estrangeira (LE) aumentam na medida em que o aluno se torna mais autônomo. Contudo, assumimos a dificuldade, senão a utopia, de definirmos esse comportamento com precisão, ou ainda, de identificarmos atitudes autônomas plenas por parte dos aprendizes, visto que se trata de um comportamento dinâmico, com períodos de avanço e de recuo (PAIVA, 2005).

Nesta pesquisa investigamos quais atitudes do aprendiz de FLE auxiliam na condução de um caminho em busca da autonomia na aprendizagem. Para tanto, buscamos identificar e analisar a influência da motivação (GARDNER, 1972), das concepções dos alunos sobre aprendizagem e do emprego de estratégias de aprendizagem (COSCARELLI, 1997).

Além disso, é necessário que se considere que ainda existe resistência, tanto por parte de professores, quanto pelos alunos no sentido de encontrar um equilíbrio no que concerne á autonomia. O primeiro, resiste em assumir uma atitude que privilegie a autonomia em detrimento do controle sobre a sala de aula; já o segundo, insiste em não romper com uma atitude passiva em relação à sua aprendizagem. Assim, buscamos discutir, ainda que em linhas gerais, a importância do professor para a modificação da postura dos aprendizes e, até mesmo, de sua própria atitude diante da situação de ensino/ aprendizagem/ aquisição da língua estrangeira. 
Com base nessa realidade e considerando que cada aprendiz é responsável por determinar como, quando e onde ele deseja aprender, acreditamos que nossa pesquisa fornecerá subsídios para a discussão sobre a importância de encararmos o aluno como centro no processo de aprendizagem. Desse modo, acreditamos que a análise das suas motivações e o incentivo pelo uso e pela tomada de consciência sobre suas estratégias individuais se configuram como ponto de partida para se alcançar uma maior reflexão e atingir um maior grau de desenvolvimento na aprendizagem do francês como língua estrangeira.

\section{Autonomia na aprendizagem}

Do ponto de vista da didática de línguas, estabelece-se uma distinção bastante útil entre aprendizagem e aquisição de uma LE: enquanto a primeira está associada ao meio institucional, ou seja, a um contexto preparado conscientemente para o seu desenvolvimento, a segunda se associa ao meio natural (CUQ, 2003, p.12).

Adquirir uma língua significa produzir ou compreender um enunciado sem necessariamente possuir consciência lingüística; ou seja, atuar na LE sem pensar nas operações que executamos, enquanto aprender a LE significa monitorar a comunicação, tomando consciência sobre seu funcionamento (BERTOCCHINI e CONSTANZO, 1989, p. 53).

Consideramos que a aprendizagem resulta de um processo consciente, “definido como um conjunto de decisões relativas às ações a serem tomadas, com o intuito de adquirir saberes em língua estrangeira” (CUQ, 2003, p 22). Desse modo, admitimos que as ações dos aprendizes são dirigidas por uma preocupação em elaborar uma prática consciente e que “o aprendiz é um locutor provido de estratégias que sustentam seus conhecimentos e resolvem suas dificuldades de comunicação em LE (CUQ e GRUCA, 2002, p. 112)

Acreditamos, assim, que um estudo sobre a autonomia dos aprendizes é, antes de tudo, um estudo sobre como eles atuam num processo consciente e como a conscientização sobre esse processo auxilia, gradativamente, no desenvolvimento de atitudes mais autônomas. 
Segundo Paiva (2005), definir autonomia não é uma tarefa fácil, já que existem poucas situações nas quais os aprendizes podem ser realmente autônomos. Isto acontece porque, normalmente, os alunos não são totalmente livres de interferências de fatores externos.

Além disso, se tentamos responder à questão $O$ que é autonomia? de maneira imediata, é comum que se pense em autonomia como uma capacidade de trabalhar sozinho. No entanto, a palavra autonomia não se relaciona à independência; ao contrário, no contexto de aprendizagem de LE, elas podem ser consideradas opostas. (PORTINE, 1998)

Assim, verificam-se dois erros fundamentais para o tipo de resposta que relaciona autonomia à independência: a) ela considera que a autonomia é puramente individual, enquanto a autonomia supõe uma relação complexa entre aprendiz e professor e, b) ela considera que autonomia se obtém ou se adquire por um salto qualitativo brutal, enquanto trata-se de um processo em espiral, com recuos, com avanços, com fases de latência e progressão lentas.

Neste trabalho, tomamos como orientação o conceito de autonomia dado por Paiva (2005, p.6), pois parece ser o mais abrangente, uma vez que privilegia a complexidade do termo na tentativa de englobar conceitos já discutidos e propõe a seguinte definição:

Autonomy is a complex socio-cognitive system, manifested in different degrees of independence and control of one's own learning process, involving capacities, abilities, attitudes, willingness, decision making, choices, planning, actions, and assessment either as language learner or as a communicator inside or outside the classroom. As a complex system it is dynamic, chaotic, unpredictable, non-linear, adaptative, open, self-organizing, and sensitive to initial conditions and feedback. ${ }^{1}$

A tomada de consciência dos próprios problemas pelos aprendizes e dos caminhos para resolvê-los se configura em um ponto de partida para tornar o processo de aprendizagem mais eficiente. Esse novo caminho envolve, segundo Barcelos (2003,

\footnotetext{
${ }^{1}$ [...] autonomia é um sistema sócio cognitivo complexo manifestado em diferentes graus de independência e controle do processo de aprendizagem de cada pessoa, envolvendo capacidades, habilidades, atitudes, vontades, decisão de agir, escolhas, planejamento, ações e avaliação, por parte do aprendiz ou do comunicador, dentro ou fora da sala de aula. Como um sistema complexo ele é dinâmico, caótico, imprevisível, não-linear, adaptativo, aberto, auto-organizante, e sensível às condições iniciais e feedback. (tradução das autoras)
} 
p. 66), a consciência sobre o processo de aprendizagem, a auto-motivação e a autoconfiança.

Na busca pela promoção da autonomia do aluno, o professor deve ter em mente os seguintes objetivos: aumentar a conscientização do aprendiz sobre como ele conceitua a sua própria aprendizagem e como ele se vê como aprendiz, promover a auto-motivação para a aprendizagem da língua, desenvolver a autoconfiança do aprendiz e a sua consciência sobre o processo de aprendizagem. (BARCELOS, 2003, p. 66)

Consideramos de inestimável valor para o ensino / aprendizagem de LE que a autonomia do aprendiz seja cotidianamente discutida, permitindo-se, dessa maneira, que o processo de autonomização (no sentido de movimento) da aprendizagem venha a ser, para o aprendiz e também para o professor, cada vez mais eficaz, garantindo maior desenvolvimento e melhor desempenho na aprendizagem da língua alvo.

\section{Procedimentos Metodológicos}

A presente pesquisa foi realizada a partir de observação de aulas e de aplicação de questionários em duas turmas de Francês na cidade de Campina Grande - PB, com alunos de nível A1, segundo o Quadro Europeu Comum de Referência para as Línguas (CECRL, 2001).

Na primeira turma, inicialmente, sete (7) participantes freqüentavam o curso de língua francesa, com objetivo principal de comunicação. Ao final, apenas cinco (5) dos alunos iniciais responderam os questionários. O outro grupo era formado por quatro (4) alunos do curso de graduação em Letras / Francês da universidade pública local; isto é, professores em formação. Dentre os alunos que freqüentavam as aulas, apenas três (3) responderam os questionários. Na análise dos dados, as referidas turmas foram dividas em grupo 1 (G1) e grupo 2 (G2), respectivamente.

Os procedimentos metodológicos para a realização desta pesquisa se deram em duas etapas: A primeira constou de observação, gravação e anotações de oito (8) aulas de 50 minutos em cada turma, pois consideramos a observação das aulas uma etapa importante para auxiliar na elaboração do questionário e também como apoio para as discussões, quando necessário. 
A segunda etapa consistiu na aplicação de um questionário estruturado da seguinte maneira: perfil do aluno, perfil da aprendizagem e noções de aprendizagem. Procuramos identificar as ações dos alunos ao aprender o FLE, abrangendo questões relativas à motivação, consciência sobre o processo de aprendizagem e estratégias individuais. Para categorização das estratégias individuais nos valemos da classificação e descrição de atitudes proposta por Paiva (1998).

Com base na observação de aulas e na análise dos dados, procuramos identificar, a partir de depoimentos guiados por questões sobre a aprendizagem, quais eram as concepções e crenças, bem como as estratégias utilizadas pelos aprendizes de FLE. Após essas observações, identificamos o grau de autonomia dos alunos, analisando como cada elemento comportamental auxilia no desenvolvimento da autonomia na aprendizagem de línguas.

\section{Análises dos dados}

A elaboração do questionário foi fundamentada ao se considerara que a participação do aprendiz na autodireção se situa nos "níveis de determinação dos objetivos, definição de conteúdos e sua progressão, seleção de métodos e técnicas, controle do desenvolvimento da aquisição e avaliação” (ANDRE, 1989, p. 105).

A escolha das turmas foi motivada, em princípio, pela hipótese de que, em se tratando de turmas com objetivos e necessidades de aprendizagem diferentes, os resultados apontariam para uma reflexão sobre o efeito da motivação para o desenvolvimento de uma atitude autônoma por parte do aprendiz de FLE. Um grupo era composto por alunos do curso de Licenciatura em Letras - Língua Francesa (formadores em formação) e o outro por alunos que desejam aprender FLE com o único objetivo de comunicação.

A motivação do aprendiz é um sentimento que contribui para o seu engajamento na realização de tarefas e em tomadas de posições comportamentais que auxiliam o aprendizado, tais como se sentir seguro, interessar-se pelas atividades que lhe são significativas e viver sua autonomia.

É importante que se destaque a prática da observação de um comportamento em termos de motivação como um elemento favorecedor uma explicações sobre o porquê 
de tal comportamento. Assim, assumimos que o contexto situacional é o ponto de partida para que o sujeito tenha atitudes motivadas e também que a definição das suas necessidades, dos seus interesses e dos seus objetivos de aprendizagem é determinante no sucesso do aprendiz.

Pensando nisso, na parte intitulada perfil do aluno no questionário, identificamos a faixa etária dos alunos (19 a 27 anos) e ocupação (estudantes universitários e profissionais). Em seguida, no perfil da aprendizagem, apresentamos oito questões aos alunos, das quais, apresentaremos aqui quatro questões que consideramos centrais na determinação dos objetivos e envolvimento do aluno na própria aprendizagem.

Inicialmente, com o intuito de verificar categorias de motivação para a aprendizagem, questionamos:

1) Por que você estuda uma língua estrangeira?

2) Por que você escolheu o francês como língua estrangeira?

Organizamos, então, as informações recolhidas citando os motivos apontados pelos alunos e a sua recorrência. Vejamos, na Tabela 1, os dados referentes à primeira questão e na Tabela 2, os referentes à segunda:

TABELA 1: Motivação para o aprendizado de LE

\begin{tabular}{|l|l|l|}
\hline Motivação para aprendizado de LE & G1 & G2 \\
\hline 1. Profissional (necessidade qualificação para o mercado) & 3 & 1 \\
\hline 2. Prazer e/ou curiosidade em aprender novas línguas/culturas & 3 & 1 \\
\hline 3. Viagem de estudos/trabalho & 2 & 1 \\
\hline 4. Outros & --- & 1 \\
\hline
\end{tabular}

Observamos a ocorrência de sete (7) citações que apontam para uma motivação instrumental, que diz respeito a razões pragmáticas e utilitárias (Gardner, 1972), que foram enquadradas nas categorias: "profissional” e "viagem de estudos/ trabalho" e cinco (5) citações que fazem parte do grupo que Gardner chamou de motivação integrativa, na qual o conhecimento sobre outra comunidade lingüística é a principal razão pela qual o aprendiz estuda uma LE. 
TABELA 2: Motivação para aprendizado de FLE

\begin{tabular}{|l|l|l|}
\hline Motivação para aprendizado de FLE & G1 & G2 \\
\hline 1. Qualificação profissional & 1 & --- \\
\hline 2. Prazer e/ou curiosidade em aprender língua/cultura francesa & 3 & 2 \\
\hline 3. Viagem à França por motivo de estudos/trabalho & 3 & 1 \\
\hline 4. Escolha de uma 3a língua & 1 & 1 \\
\hline 5. Outros & 1 & --- \\
\hline
\end{tabular}

Confrontando as duas tabelas, constatamos que a principal diferença em relação aos dados anteriores é a especificação do interesse pela língua e pela cultura francesa. No que diz respeito à definição dos objetivos, todos os alunos apresentaram consciência sobre o motivo pelo qual estuda língua francesa, fato que se configura como um passo significativo no desenvolvimento da autonomia.

Sabemos que a consciência do aluno sobre o seu papel e suas responsabilidades na aprendizagem é fundamental para o desenvolvimento da sua autonomia, pois é partir desse entendimento que poderá exercer o próprio conceito de autonomia e se tornar responsável pelo próprio aprendizado.

Diante disso, formulamos duas questões sobre a responsabilidade pela aprendizagem e sua relação com o desenvolvimento pessoal e do grupo:

3) No que concerne ao pacto de responsabilidade na aprendizagem, quais das questões abaixo você assinala como importantes?

4) Você se considera responsável pelo desenvolvimento do grupo? Por quê? De que maneira?

Para responder à primeira questão o aluno dispôs de cinco (5) alternativas, assim como aparecem na Tabela 3, podendo escolher mais de uma e, em seguida, requisitamos que ele justificasse suas escolhas a fim de fosse explicitado como essa responsabilidade é posta em prática.

TABELA 3: Elementos envolvidos no processo de ensino-aprendizagem 


\begin{tabular}{|l|l|l|}
\hline O professor é o principal responsável pelo meu desenvolvimento & --- & 1 \\
\hline Eu sou o principal responsável pelo meu desenvolvimento & 3 & 1 \\
\hline As responsabilidades são dividas entre professor e aluno & 2 & 2 \\
\hline Depende da instituição de ensino & --- & --- \\
\hline Depende do método (livro) escolhido & 1 & \\
\hline
\end{tabular}

Segundo os dados apresentados, todos os alunos do grupo 2 (G2) escolheram a alternativa em que as responsabilidades são divididas entre professor e aluno, sendo que um deles marcou a primeira e segunda opções, talvez por não ter realizado uma leitura detida de todas as opções. Tal fato apóia a idéia de que os alunos participantes desta pesquisa possuem um grau de conscientização satisfatório, pois se colocam, em maioria, como o principal elemento envolvido na própria aprendizagem.

Em resposta à quarta questão, todos os alunos se consideram responsáveis pelo desenvolvimento do grupo. Nesta pergunta, não enquadramos as respostas em categorias, como fizemos nas anteriores, pois não observamos tipos de respostas recorrentes fixas. Analisamos, assim, algumas das informações sobre como cada um acredita ter influência sobre o grupo:

- Sim, porque em sala todos aprendem e erram juntos. (A5 G1)

Para comentarmos o exemplo acima recorremos à atenção dada ao erro sob a ótica da abordagem comunicativa. A conscientização sobre a sua importância no processo de ensino-aprendizagem é determinante para um comportamento autônomo do aprendiz, pois ele reconhece que o erro é muito mais um elemento constitutivo do processo que uma falha própria, o que viria a sustentar a sua autoconfiança. Observamos que o participante 5 (A5) tem essa consciência e considera ainda que os seus erros, ao serem corrigidos em sala de aula, podem auxiliar no progresso do grupo, assim como os erros do grupo auxiliam na sua aprendizagem.

Em seguida, os alunos citam a comunicação na língua-alvo em sala de aula como a principal contribuição que podem dar um ao outro. Nesse caso, observa-se que a aquisição da língua é posta em valor: 
- Sim. Porque o interesse pela aprendizagem de cada um contribui para o desenvolvimento de todos do grupo. Por exemplo, se na aula de francês todos se esforçam para se comunicar apenas em francês, o rendimento do aluno será melhor. (A3 - G1)

- Sim, pois posso influenciar os alunos a manterem contato em francês. $(A 8-G 2)$

Finalmente, a homogeneidade da turma em relação aos objetivos é relevada pelo aluno 3 (A3), que usa o termo unido provavelmente para fazer referência à presença de objetivos comuns: - Quando o grupo é bastante unido, podemos dizer que cada componente interfere no desenvolvimento. (A1-G1)

Concluímos aqui que todos os alunos se consideram responsáveis pelo seu próprio aprendizado. Seja considerando-se o principal responsável, seja dividindo a sua responsabilidade com o professor, todos eles demonstram consciência sobre a importância do comprometimento e empenho do aluno no desenvolvimento da aprendizagem.

Além disso, em todos os depoimentos, observamos ainda uma importância relevada ao envolvimento do aprendiz com o grupo no estabelecimento de trocas de conhecimentos, de superação de dificuldades e de desenvolvimento da competência lingüística.

Entendendo a conscientização sobre o processo de aprendizagem pelo próprio aprendiz como um dos objetivos principais a serem alcançados na busca pela promoção da autonomia, partimos para a análise da parte noções de aprendizagem do questionário, na qual procuramos identificar conceitos pessoais de aprendizagem questionando:

5) Para você, o que é aprendizagem?

6) Sob o seu ponto de vista, como você aprende?

7) Você acredita que utiliza alguns recursos /meios/ estratégias para a sua própria aprendizagem? Quais?

Para a primeira questão, analisaremos os exemplos que seguem: - É o processo pelo qual nos é apresentado algo, analisamos, selecionamos o que é válido $e$ memorizamos. (A5 - G1)

Esse aluno explicita em seu depoimento um entendimento sobre estratégias que influenciam diretamente na aprendizagem como estratégias cognitivas de análise e síntese do material de aprendizagem e estratégias de memória. Para ele, a aprendizagem 
depende do professor que é o responsável pela apresentação de conteúdos e esse é o passo inicial para a construção da aprendizagem, sendo definido como o próprio processo de aprendizagem.

Nos exemplos seguintes, os alunos parecem possuir uma visão mais ampla da noção de aprendizagem, descrevendo-a como desenvolvimento de competência comunicativa, exemplificando com "situações cotidianas"; "situações diversas" e também sugerindo a necessidade/desejo de aprender como o objetivo maior e motivador. É interessante observar que demonstram ainda a autonomia numa relação de independência na sala de aula:

- Tudo que se faz para aprender de tudo, ou seja, todo o trabalho que se faz para aprender a partir de qualquer recurso, mesmo situações cotidianas. (A4 - G1)

- Se apropriar de forma crítica de um conhecimento e estar apto à utilizá-lo em situações diversas. (A8-G2)

Nesses depoimentos aparecem também conceitos de estratégia e tarefa, tal como observamos em “o trabalho que se faz para aprender a partir de qualquer recurso", no qual o trabalho parece estar associado à tarefa e recurso às estratégias pessoais que ele utiliza ou busca. Evidenciamos também, com a expressão da idéia de “apropriação de um conhecimento de forma crítica”, a utilização de uma estratégia metacognitiva, que relaciona um conhecimento prévio a uma informação nova a fim de lhe atribuir significado, a partir das experiências de vida, conhecimento de mundo e relevância para o aprendiz.

Em outros dois exemplos, o conteúdo é o foco da aprendizagem. Para esses alunos, o sucesso da aprendizagem depende do quanto o conteúdo apresentado em sala de aula é assimilado. No segundo, acrescenta-se a idéia de isenção de dúvidas, o que demonstra uma visão, do aluno, de aprendizagem muito mais como produto, saber adquirido, do que como processo:

- É quando eu consigo absorver os conteúdos ministrados na sala. (A3 - G1)

- Aprendizagem é a percepção que você tem quando um certo conteúdo passa a ser assimilado com mais clareza, sendo isento de dúvidas.”(A1 - G1) 
Por fim, observamos mais dois exemplos que utilizam o termo aquisição para conceituar aprendizagem:

- Aprendizagem é o conhecimento que se adquire e não se esquece. (A6 - G2)

- É adquirir novos conhecimentos (A2 - G1)

Percebe-se que aquisição, na visão dos alunos tem um caráter de conhecimento definitivo, tratando-se de uma ação a partir da qual os conteúdos (“conhecimentos”) são assimilados por um longo período. Os alunos parecem desprezar, no entanto, a aprendizagem como processo, como algo que se constrói e sobre o qual eles podem interferir ativamente.

Partindo para a análise da segunda questão, verificamos a ocorrência de dois modelos de respostas que figuram na Tabela 4:

TABELA 4: Como se aprende uma LE?

\begin{tabular}{|l|l|l|}
\hline Como se aprende uma LE? & G1 & G2 \\
\hline Com o professor em sala de aula & --- & 2 \\
\hline Utilizando estratégias pessoais & 5 & 1 \\
\hline
\end{tabular}

Vemos que em todas as respostas do grupo 1 (G1) os alunos indicaram estratégias pessoais que auxiliam no aprendizado, enquanto apenas um dos alunos do grupo 2 (G2) cita esse tipo de estratégia. Nos dois casos do grupo 2 (G2) a aula e o professor foram citados como as principais fontes de conhecimento ou maneiras de aprender, os alunos agem passivamente, esperando as orientações do professor, não conseguindo exercer sua autonomia:

- Com as aulas, com os recursos trazidos para a realização da mesma e com exercícios. (A7 - G2)

- Nunca parei para pensar como eu aprendo. O processo de aprendizagem se dá de forma tão natural que por vezes me surpreendo por perceber que já aprendi tanta coisa. Minha 
maior fonte é a sala de aula e a professora. Tento prestar bastante atenção e seguir as orientações. (A8 - G2)

Enquanto isso, os cinco (5) alunos do grupo 1 (G1) citam estratégias pessoais variadas:

- De várias formas, mas para mim é sempre mais fácil quando está relacionado a alguma imagem. (A4 - G1)

- Escutando e lendo. (A5 - G1)

- Só aprendo escrevendo (repetindo). Só lendo, esse método ${ }^{2}$ comigo não funciona. Quando transcrevo percebo que estou aprendendo mais. (A1 - G1)

-Lendo, fazendo alguns exercícios, e tento sempre formular frases em francês quando estou só pensando em coisas para fazer ou quando vou falar com as pessoas. (A3 - G1)

Nesse momento, esperávamos que os alunos respondessem livremente o tipo de estratégias que utilizavam para auxiliar na aprendizagem, antes de passarmos para a Parte II do questionário. Na segunda parte, eles escolheriam as próprias estratégias a partir de uma lista de atitudes que podem ser tomadas por aprendizes de LE.

Os participantes dos grupos G1 e G2 citam as estratégias pessoais que são registradas na Tabela 5, de acordo com o número de vezes que foi citada por cada grupo:

TABELA 5: Estratégias individuais de aprendizagem

\begin{tabular}{|l|l|l|}
\hline Estratégias individuais de aprendizagem & G1 & G2 \\
\hline Escutar músicas em francês & 3 & 2 \\
\hline Ler & 2 & --- \\
\hline Assistir a filmes & 1 & --- \\
\hline
\end{tabular}

\footnotetext{
${ }^{2}$ É importante que se destaque que o aluno se refere ao método como metodologia para estudo e não ao método como sinônimo de manual (livro) para ensino de línguas.
} 


\begin{tabular}{|l|l|l|}
\hline Pensar em francês & 1 & --- \\
\hline Buscar novas informações na internet & 1 & --- \\
\hline Prestar atenção às aulas & --- & 1 \\
\hline Fazer anotações & --- & 1 \\
\hline Manter contato com a língua & 1 & 1 \\
\hline Conversar com os amigos em francês & --- & 1 \\
\hline Utilizar material didático indicado pelo professor & --- & 1 \\
\hline Organizar os conteúdos de maneira a estabelecer uma seqüência & 1 & --- \\
\hline
\end{tabular}

Dentre todas as estratégias citadas, apenas Prestar atenção às aulas e Pensar em francês não dizem respeito à utilização de estratégias cognitivas. A conscientização do emprego de processos metacognitivos e de estratégias de memória na aprendizagem representada nos dois exemplos citados é muito pequena se consideramos que oito (8) outras estratégias de ordem cognitiva são mencionadas. Ressalte-se que mesmo que um aluno tenha citado uma estratégia metacognitiva, essa ainda está relaciona ao o momento de sala de aula.

A partir da análise dos dados acima, percebemos uma variação de estratégias utilizadas entre os grupos, o que não nos permitiria, ainda que fosse esse o objetivo dessa pesquisa, ser categóricos em uma comparação entre eles. Acreditamos que, apesar de cada grupo apresentar uma tendência ou percurso diferente na busca pelo desenvolvimento da autonomia, os alunos participantes demonstram envolvimento na aprendizagem de FLE.

Podemos concluir assim que, no que concerne à conscientização do processo de aprendizagem e a sua conseqüente conceituação, os sujeitos participantes dessa pesquisa ainda têm um longo caminho a percorrer no desenvolvimento da autonomia, pois o foco em "o que fazer" em si e a quase que completa exclusão de "quando e como fazer" evidenciam uma reduzida reflexão sobre como os problemas na aprendizagem podem ser solucionados e sobre como cada um se desenvolve ou poderia alargar esse desenvolvimento.

\section{Considerações Finais}


Focalizamos nesta pesquisa a autonomia do aprendiz no contexto de aprendizagem de FLE, observando dois grupos de aprendizes que, inicialmente, se distinguem a partir da definição de objetivos: um grupo possui objetivos básicos de comunicação, enquanto o outro é formado por professores de FLE em formação inicial.

Considerando que a autonomia é um comportamento complexo, pelo seu caráter dinâmico e por envolver diversas variáveis, propomos uma análise desse comportamento a partir de três elementos fundamentais para o seu desenvolvimento: a motivação do aprendiz, o conhecimento do aprendiz sobre sua própria aprendizagem e o emprego de estratégias individuais de aprendizagem.

A partir da observação dos resultados, concluímos que as turmas, apesar de concentrarem alunos de uma faixa etária entre 19 e 27 anos com objetivos semelhantes, apresentam heterogeneidade comportamental e dinamismo no que diz respeito, principalmente, à consciência sobre o que é e como ocorre o processo de aprendizagem.

Acreditamos que esse caráter dinâmico verificado não apenas dentro das turmas, mas também em relação às atitudes do mesmo aprendiz em situações (questionamentos) diferentes, faz parte do próprio processo de aprendizagem e desenvolvimento da autonomia; pois, percebemos que em alguns momentos o mesmo aluno pode apresentar fortes indícios de atitudes autônomas, com elevado grau de consciência sobre a própria aprendizagem e, em outros, um baixo grau de consciência sobre suas práticas.

Um dado relevante sobre a consciência da responsabilização na aprendizagem merece destaque: todos os alunos questionados afirmaram que são responsáveis pela própria aprendizagem, seja como principal responsável, seja dividindo a responsabilidade com o professor. Tal fato demonstra que o caminho de conscientização progressiva a ser percorrido em busca da autonomia, juntamente com o professor, já está delimitado nos grupos analisados.

Foi possível observar, com o caminhar da pesquisa, que estabelecer parâmetros de identificação de atitudes autônomas é uma atividade difícil e que entrevistas com os alunos talvez pudessem minimizar essa identificação. No entanto, considerar que os mecanismos de análise foram satisfatórios para atender aos nossos objetivos.

Por fim, considerando a relevância do comprometimento do professor na construção da autonomia do aprendiz. A impossibilidade de abranger o aluno e o professor, nessa pesquisa, ajuda a apontar para a necessidade de um estudo que centre 
forças nas ações pedagógicas do professor no contexto de ensino-aprendizagem de FLE. Assim, cremos que será possível observar não apenas as perspectivas do aluno e suas influências, mas também e, sobretudo, como as práticas do professor podem refletir na construção de comportamentos autônomos por parte de aprendizes.

\section{Referências}

ANDRE, B. (org). Autonomie et enseignement/ Apprentissage des langues étrangères. Paris: Didier, 1989. 159p.

BAILLY, N ; COHEN, M. (2007). L'approche communicative. In Tomé (coord., 2007) Revue TOURDETOILE. Projet FLENET - RedIRIS, Universidad de Leon (Espagne). Consultado em fev. 2008 no endereço http://flenet.rediris.es/tourdetoile/

BARCELOS, A. M. F.; SERAFIM, C. A. Dando os primeiros passos para a aprendizagem autônoma. Trabalho apresentado do V Congresso de Letras: Discurso e Identidade Cultural, 2003. Consultado em jun. 2008 no endereço: http://bibliotecadigital.unec.edu.br/ojs/index.php/unec02/issue/view/2

BERTOCCHINI, P.; CONSTANZO, E. Manuel d'autoformation à l'usage des professeurs de langues. Paris: Hachette, 1989. 207p.

COSCARELLI, C. V. Estratégias de Aprendizagem de Língua Estrangeira: uma breve introdução. Educação e Tecnologia. Belo Horizonte: CEFET-MG, v. 4, n. 4, p. 23-29, jan./jul., 1997. Consultado em jan. 2008 no endereço: http://bbs.metalink.com.br/ lcoscarelli/ESTRAT.pdf

CUQ, J. P (org). Dictionnaire de didactique du français, langue étrangère et seconde. Paris : CLE Internacional, 2003. 303p.

CUQ, J.-P. ; GRUCA, I. Cours de didactique du français langue étrangère et seconde. Grenoble : Press Universitaires de Grenoble, 2002. 452p.

GARDNER, R.; LAMBERT, W. Attitudes and motivation in second language. U.S.A., Newbury House, 1972.

PAIVA, V.L.M.O. Autonomy in second language acquisition. SHARE: An Electronic Magazine by Omar Villarreal and Marina Kirac. n. 146, ano 6, May $6^{\text {th }} 2005$.

. Estratégias individuais de aprendizagem de língua inglesa. Letras Letras. v. 14, n. 1, jan./jul. 1998. p. 73-88.

PORTINE, Henri. L'autonomie de l'apprenant en questions. Points de vue. v. 1 , n. 1 , juin 1998. p. 73-77. 